\title{
A Utilização de Role Playing Games Digitais como Ferramenta Complementar no Processo de Aprendizagem de Crianças Deficientes Visuais
}

\author{
Felipe V. Sobral, Luan F. Umeres, William Schanoski, Roberta C. Bartelmebs, Marcos \\ V. O. de Assis \\ Universidade Federal do Paraná - Setor Palotina \\ Pioneiro 2153 - Dallas - Palotina/ PR \\ \{xfelipesobral, umereslf, schanoski97\}@ gmail.com, \\ \{roberta.bartelmebs,marcos.assis\}@ufpr.br
}

\begin{abstract}
The present work reports the construction of a digital game in the style Role Playing Game (RPG). This game was specifically elaborate for the work with children and adolescents with visual impairment. The main objective is the teaching of concepts in the Portuguese Language and Mathematics area for children and adolescents of Middle School I and II. The first tests with the beta version of the game demonstrated that it could be an excellent tool for digital inclusion of children and adolescents with visual impairment since it opens doors to a new type of games to be explored, as well as significant didactic-methodological support for to teachers to use in their classrooms.
\end{abstract}

Resumo. $O$ presente trabalho relata a construção de um jogo digital no estilo Role Playing Game (RPG). Este jogo foi elaborado especificamente para o trabalho com crianças e adolescentes com deficiência visual. $O$ objetivo principal é o ensino de conceitos da área da Língua Portuguesa e Matemática para crianças e adolescentes do Ensino Fundamental I e II. Os primeiros testes com uma versão de demonstração do jogo demonstraram que este pode ser uma excelente ferramenta para inclusão digital de crianças e adolescentes com deficiência visual, uma vez que abre portas para um novo tipo de jogo a ser explorado, bem como importante suporte didático-metodológico para os professores utilizarem em suas salas de aulas.

\section{Introdução}

A inclusão digital de crianças assume grande importância nos dias de hoje e, com a popularização de ferramentas computacionais e da Internet, o uso dessas ferramentas vem ganhando espaço no campo do Ensino. Estamos cada dia mais dependentes das mídias digitais, fazendo com que as novas gerações passem a interagir com elas desde muito cedo, tornando o uso dos meios tecnológicos algo natural e simples para os jovens. Como jogos digitais estão cada vez mais presentes, acreditamos na necessidade de sua inserção na escola como ferramenta didática. A sociedade contemporânea que se comunica fluentemente pela internet vem sendo analisada por teóricos como Levy (2007), que se refere a ela pelo termo cybercultura. 
Em tempos de cybercultura, conforme aponta Silva (2005), a inclusão de pessoas com deficiência visual torna-se importante para garantir sua efetiva participação em uma sociedade digital. Além disso, o uso das tecnologias nas escolas é também uma exigência da cybercultura.

Embora sejam de grande importância como ferramentas de apoio no processo de aprendizagem, crianças com deficiência visual muitas vezes são impossibilitadas de usufruir desses recursos. Por mais que exista um consenso sobre a importância da inclusão social de pessoas com deficiência e apesar desse discurso fazer parte da legislação do nosso país, esse conceito ainda não é exercido plenamente. Segundo Siqueira e Martini (2010), isso acontece por existir uma falta de recursos e ambientes educacionais voltados para deficientes visuais, limitando a gama de recursos disponíveis para este público.

No Brasil, de acordo com o censo do Instituto Brasileiro de Geografia e Estatística (IBGE, 2000), existiam cerca de 148 mil pessoas cegas e cerca de 2,4 milhões que relatam dificuldade de enxergar (MARIANO, 2010). Além disso, segundo a Organização Mundial da Saúde (2011 apud SENZ, PEREIRA, 2015) cerca de 15\% da população mundial apresenta algum tipo de "desabilidade motora, cognitiva ou sensorial". Ou seja, uma parcela considerável da população possui algum tipo de limitação que lhe impede de viver plenamente a inclusão digital.

Nesse sentido, o projeto aqui apresentado tem como principal objetivo entender como ocorre o processo de interação de deficientes visuais com sistemas computacionais na aprendizagem de conteúdos escolares e, ao mesmo tempo, identificar recursos de entretenimento para esses indivíduos. Inicialmente realizamos uma revisão bibliográfica que apontou o uso de Audio Games como uma possível solução para os referidos problemas. Audio Game é a denominação dada a um ambiente computacional interativo lúdico sem nenhum tipo de recurso gráfico. É ideal que esse tipo de jogo seja atrativo para todas as crianças, não apenas para o público deficiente visual, já que o fato de alguém jogar sozinho não significa inclusão segundo os aspectos técnicos para o desenvolvimento desse tipo de software de Yuan, Folmer e Harris Jr. (2011).

Visando compreender a interação dos alunos deficientes visuais com um Audio Game e sua eficácia no aprendizado nas áreas de Língua Portuguesa e Matemática, utilizamos a teoria construtivista da linha piagetiana, entendendo a aprendizagem como uma interação radical entre sujeito e objeto (Becker, 1994). Nosso objetivo pedagógico foi o de possibilitar a construção de novas aprendizagens, integrando conteúdos que os alunos já conheciam com os desafios apresentados no decorrer do jogo. Escolhemos as disciplinas citadas com base em um levantamento de dados na Secretaria Municipal de Educação de Palotina/PR, nos quais constatou-se que alunos com deficiência visual possuem maior dificuldade de aprendizado nessas áreas.

Além disso, entendemos que os jogos digitais desempenham importante papel pedagógico no ensino. De acordo com Machado (1995, p. 199) quando se considera o papel dos jogos nas atividades didáticas, as dimensões lúdica (em sentido restrito) e utilitária (jogos que servem para introduzir certos temas) se destacam. A primeira refere-se ao divertimento e à brincadeira, enquanto a segunda trata dos resultados educativos propriamente ditos a serem alcançados. Dessa forma o lúdico e o utilitário podem ser explorados em um jogo eletrônico, de modo a possibilitar também inclusão digital das crianças e adolescentes com deficiência visual. 
VI Congresso Brasileiro de Informática na Educação (CBIE 2017)

Anais do XXVIII Simpósio Brasileiro de Informática na Educação (SBIE 2017)

\section{Referencial Teórico}

A seguir apresentamos a fundamentação teórica que embasou nossa pesquisa acerca do uso de jogos digitais na aprendizagem de crianças com deficiência visual. Dividimos o texto em duas seções. A primeira seção apresenta uma revisão sobre a utilização de jogos digitais no Ensino Fundamental e a segunda seção discorre sobre a acessibilidade de jogos digitais para pessoas com deficiência visual.

\section{Utilização de jogos digitais no Ensino Fundamental}

Atualmente a aprendizagem de alunos cegos é uma preocupação constante para os professores (Lopliane, Batista, 2003). Há necessidade de conhecer novos recursos que possibilitem aos alunos com deficiência visual desenvolverem plenamente suas habilidades cognitivas. Assim surgem alguns questionamentos sobre como essas crianças podem aprender novos conceitos, como distinguem os objetos, seres vivos e como constroem noções geográficas, por exemplo. Mas para além dessas questões empíricas do seu cotidiano, essas reflexões nos remetem a questões epistemológicas ainda mais profundas, tais como "o que é aprender"?, "o que é conhecer"? e "como construímos conhecimento sobre o mundo"?

Conforme aponta Guarnieri (2005), se levarmos em conta a aprendizagem empírica, podemos inferir que mais ou menos $90 \%$ das informações que abstraímos do mundo são obtidas por meio do sentido da visão. Isso poderia, segundo a autora, significar um obstáculo a mais para a aprendizagem das crianças com deficiência visual.

Segundo a Lei no .9 .394 de Diretrizes e Bases da Educação Nacional, capítulo V, artigo 59 $9^{\circ}$, parágrafo I, a Educação Especial deve funcionar de modo a evidenciar conceitos de integração e inclusão, de modo que possua "I - currículos, métodos, técnicas, recursos educativos e organização específicos, para atender às suas necessidades;" (Brasil, 1996). Em outras palavras, ações específicas devem ser tomadas de modo a proporcionar ambientes eficientes tanto de inclusão social quanto de desenvolvimento educacional para pessoas com deficiência visual.

De acordo com Silva (2009, p.3), “a inclusão passou a ser assunto primordial na Educação e mostrou-se ser benéfica para todos os alunos, independente de suas habilidades ou dificuldades". A inclusão tornou-se um dos itens mais importantes na área da Educação pois, através dela, almejamos que alunos com deficiências visuais também consigam ter um ensino regular de qualidade, como os demais alunos. Conforme apontam Salton, Maia e Rosito (2011) atualmente existem muitas ferramentas que possibilitam a inclusão digital de crianças com deficiência visual. Além disso a importância dos jogos digitais, com os quais as crianças têm contato cada vez mais cedo, tornou-se necessária para que o professor possa acompanhar os interesses dos alunos (Veen, Vrakking, 2009).

Nesse contexto onde a diversificação é imensa, dificilmente alguma criança crescerá muito distante do "mundo dos games", visto que isso lhe traz benefícios, como aponta Tajra (2002, p.114): "A informática contribui para o desenvolvimento das habilidades de comunicação e de estrutura lógica de pensamento". E ainda, como aponta Hsiao (2007), os 
jogos educacionais demonstram ter alta capacidade para divertir e entreter as pessoas ao mesmo tempo em que incentivam o aprendizado por meio de ambientes interativos e dinâmicos.

Uma aprendizagem contextualizada nos interesses dos alunos tende a aproximá-los daquilo que o professor deseja que compreendam. Os jogos permitem certa liberdade, criatividade e autonomia. São interativos e desafiadores. São interessantes para as crianças justamente por se diferenciarem dos contextos educativos que frequentam na escola.

Outra vantagem dessa ferramenta de ensino e de aprendizagem, é que o educando pode obter conhecimento em várias áreas em apenas um jogo. É possível desenvolver a interdisciplinaridade (Japiassu, 1976), sendo que um único jogo pode abranger conceitos de diferentes áreas sem precisar segregá-las. Portanto, a utilização de jogos é altamente recomendável como ferramenta de ensino e de inclusão dos alunos deficientes visuais. No entanto, como veremos a seguir, ainda estamos distantes de uma ampla divulgação de recursos computacionais, especialmente com relação à diversidade de jogos, voltados para deficientes visuais em nosso país.

\section{A acessibilidade de jogos digitais para pessoas com deficiência visual}

Segundo Siqueira e Martini (2011), existe uma falta de recursos gerais em ambientes computacionais voltados a pessoas com deficiência visual, o que limita grandemente a gama de recursos, educacionais ou não, disponíveis para utilização por este público, mesmo existindo um consenso sobre a importância da inclusão social destes, e esse discurso fazer parte da realidade legislativa do país. Ainda segundo o autor: "Há uma carência de produção científica sobre essa prática, que demanda atenção urgente de pesquisadores e profissionais que tenham conhecimentos a compartilhar" (Idem, p.13). Isso evidencia uma falta de produção científica na área da acessibilidade de deficientes visuais, mas este cenário não se limita à academia, sendo observado até mesmo em setores como o entretenimento (Sens, Pereira, 2015).

Objetivando entender como ocorre a interação de deficientes visuais com sistemas computadorizados, bem como visando identificar os recursos de entretenimento disponíveis para estes indivíduos, um termo essencial às pesquisas de acessibilidade de jogos eletrônicos é interface Audio Game, que designa jogos eletrônicos que interagem com o jogador apenas através de sons, com pouco ou nenhum recurso gráfico. Segundo Yuan, Folmer e Harris Jr. (2011), a estratégia mais utilizada no desenvolvimento de jogos acessíveis para deficientes visuais é a substituição de feedback visual por outras formas as quais o jogador seja capaz de interagir, como o feedback auditivo ou tátil.

Um grande objeto de estudo analisado foi o DOSVOX ${ }^{1}$, que se configura como uma das ferramentas tecnológicas mais importantes no ramo de inserção dos deficientes visuais ao mundo digital e de autoria brasileira, o qual vem sendo amplamente utilizado em diversas pesquisas, tais como em Silveira e Martini (2011) e Barbosa, Martins e Santos (2013). O DOSVOX foi desenvolvido no ano de 1996, pela Universidade Federal do Rio de Janeiro (UFRJ), com o objetivo de auxiliar os deficientes visuais a interagir com o computador, executando tarefas, como por exemplo, a edição de textos (com impressão normal ou em

\footnotetext{
${ }^{1}$ http://intervox.nce.ufrj.br/dosvox/
} 
VI Congresso Brasileiro de Informática na Educação (CBIE 2017)

Anais do XXVIII Simpósio Brasileiro de Informática na Educação (SBIE 2017)

Braille), a leitura e audição de textos e utilização de ferramentas como calculadora, agenda e reprodutor de músicas. O sistema interage com o deficiente visual através de uma síntese de voz em Língua Portuguesa, podendo ser configurado para outros idiomas, além de possuir também sua versão para a plataforma Linux, chamada Linvox. Ambas as versões são capazes de interagir com outros programas de acessibilidade para deficientes visuais (como Virtual Vision, ampliadores de tela e etc).

Embora o DOSVOX seja uma excelente plataforma de inclusão para deficientes visuais, a gama de jogos disponíveis na mesma não é extensa (20 jogos), além do fato de que tais jogos são bem simples em sua maioria (forca, jogo da memória, paciência, entre outros). Durante a pesquisa desenvolvida, foram encontrados 2 repositórios de jogos mais complexos. O primeiro deles é um website brasileiro Audiogames ${ }^{[2]}$, o qual possui um repositório de jogos que, em sua maioria, estão em português ou são simples o suficiente para que a língua não seja um fator limitante. Este repositório possui um acervo de 34 jogos, com um diferencial de possuir jogos mais complexos e elaborados.

Entretanto estes números são muito pequenos, se comparados ao segundo repositório encontrado, Audiogames ${ }^{[3]}$, o qual é um repositório internacional que reúne em seu acervo 551 jogos baseados em áudio ou acessíveis, principalmente na língua inglesa. Além disso, neste repositório internacional apenas 5 jogos novos foram lançados no último ano.

Estes dados demonstram que, embora exista uma ampla gama de jogos adaptados ou direcionados à comunidade deficiente visual, grande parte destes jogos se encontra em língua inglesa, o que se torna uma barreira para sua utilização principalmente por crianças. $\mathrm{O}$ acervo de jogos em português ainda é pobre, tanto para iniciativas educacionais quanto de entretenimento.

Partindo para os aspectos técnicos do desenvolvimento de jogos acessíveis para deficientes visuais, segundo Yuan, Folmer e Harris Jr. (2011, p. 90), em Audio Games a substituição de recursos visuais por auditivos ocorre pelos aspectos:

Discurso ou fala: Pode ser provida tanto por leitores de tela quando texto está disponível quanto usando narração gravada. Dicas audíveis: Utilizar sons do mundo real, tais como o som do vento ou de passos, para prover informações ou dicas ao jogador;

Sonorização: Utilizar sons "não -falados" para transmitir informações usando mudanças de tom, amplitude ou tempo. Diversas estratégias de sonorização podem ser utilizadas, tais como ícones sonoros, recursos de sonar e uso de diferentes tons sonoros para distinção entre objetos ou ações.

É ideal que um jogo inclusivo seja atrativo para todas as crianças e se possível para adultos, e não só para o público deficiente visual, já que o fato de alguém jogar sozinho não significa inclusão. Se este objetivo for alcançado, teremos, além da inclusão de crianças com

\footnotetext{
2 http://www.audiogames.com.br

${ }^{3}$ http://www.audiogames.net
} 
VI Congresso Brasileiro de Informática na Educação (CBIE 2017)

Anais do XXVIII Simpósio Brasileiro de Informática na Educação (SBIE 2017)

deficiência visual na sociedade, um interesse próprio da sociedade em participar do dia-a-dia de pessoas cegas.

\section{Metodologia}

Apresentamos a seguir o caminho metodológico escolhido, nosso referencial metodológico e também o desenvolvimento das etapas deste trabalho bem como detalhes acerca da coleta de dados realizada.

A metodologia adotada no desenvolvimento deste trabalho é de cunho qualitativa (Bogdan, Biklen, 1994; Flick, 2009; Lüdke, André, 2013). Entendemos que na pesquisa qualitativa o pesquisador, ao interpretar e analisar os dados que obtêm, reconstrói a realidade, criando assim uma nova versão do todo. Nesse sentido, nossa pesquisa trata também de uma investigação- (Tripp, 2005), no sentido de que retroalimentamos nossa intervenção através do olhar da pesquisa sobre a realidade.

Inicialmente coletamos dados sobre a realidade a ser investigada, através de entrevistas na Secretaria Municipal de Educação da cidade de Palotina/PR, e também no Centro de Atendimento Especializado para Deficientes Visuais (CAEDV) da mesma cidade. Posteriormente realizamos uma entrevista com alguns alunos do CAEDV.

A partir desta informação, desenvolvemos o Audio Game utilizando a linguagem de programação Java, no formato de Role Playing Game (RPG), ou jogo de interpretação de personagem. O jogo narra a história de $\mathrm{ROH}$, uma criança cega que vive numa cidade controlada por um robô maligno que, junto de seu amigo robô chamado PI, embarca em uma aventura para salvar a cidade futurista onde vive.

Durante o jogo, o jogador precisa resolver algumas situações-problemas, nas quais são inseridos conhecimentos conceituais nas áreas de Matemática e Língua portuguesa trabalhados na Educação Básica e que foram solicitados pelos professores do CAEDV.

\section{Coleta de Dados}

A coleta de dados foi feita com base em entrevista semiestruturada aplicada à 10 crianças estudantes do CAEDV, abordando pontos como convivência entre professores e alunos, relação e interação entre os próprios alunos, conteúdos com maiores dificuldades de aprendizagem, uso de computadores, tipos de jogos que costumam jogar em casa etc.

Em um segundo momento apresentamos o jogo para os alunos do CAEDV e também para alunos do curso de Licenciatura em Computação da Universidade Federal do Paraná. Os participantes foram convidados a jogar a versão de demonstração do Audio Game e posteriormente responder a um questionário semi-estruturado com perguntas abertas e fechadas sobre a jogabilidade e interatividade do Audio Game.

\section{Resultados e análise dos dados}


VI Congresso Brasileiro de Informática na Educação (CBIE 2017)

Anais do XXVIII Simpósio Brasileiro de Informática na Educação (SBIE 2017)

Os testes realizados com o jogo na sua versão inicial foram feitos com cerca de 15 pessoas, com idades entre 10 e 22 anos. O teste foi realizado em um período de vinte dias.

A interface visual do jogo é apenas uma janela com a logo do jogo e toda ambientação acontece através do som. A interface é baseada na utilização de efeitos sonoros e narrações com instruções que levam os jogadores a fazerem suas escolhas. Caso errem muitas vezes o usuário recebe uma dica de como prosseguir.

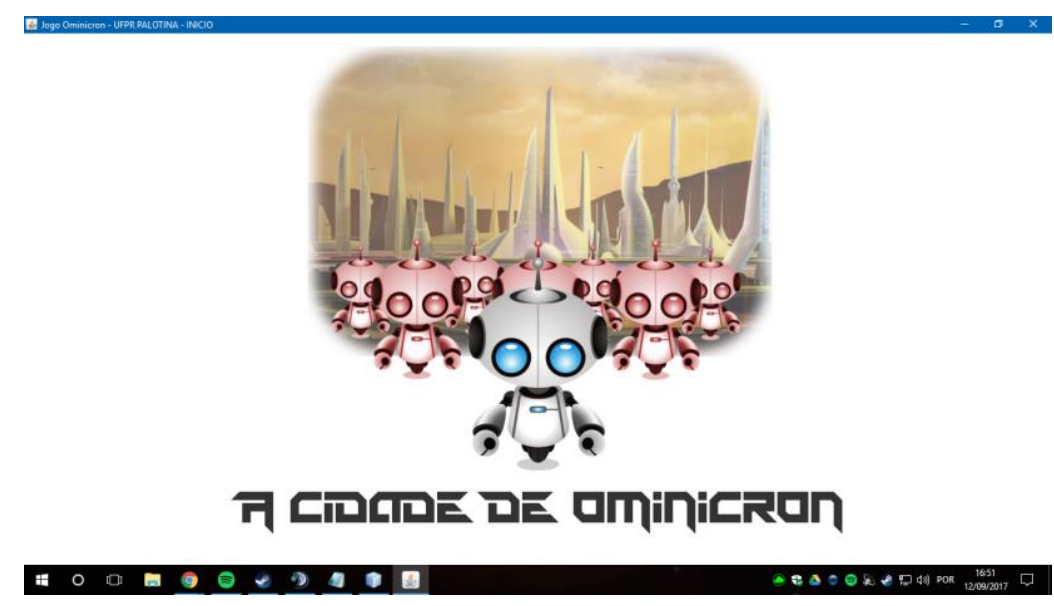

Figura 1 - Tela de abertura do jogo

Foram avaliados os seguintes aspectos do jogo: Entendimento da história, facilidade em compreender os diálogos do jogo e facilidade em compreender os comandos do jogo.

\section{Facilidade de entender os diálogos}

15 respostas

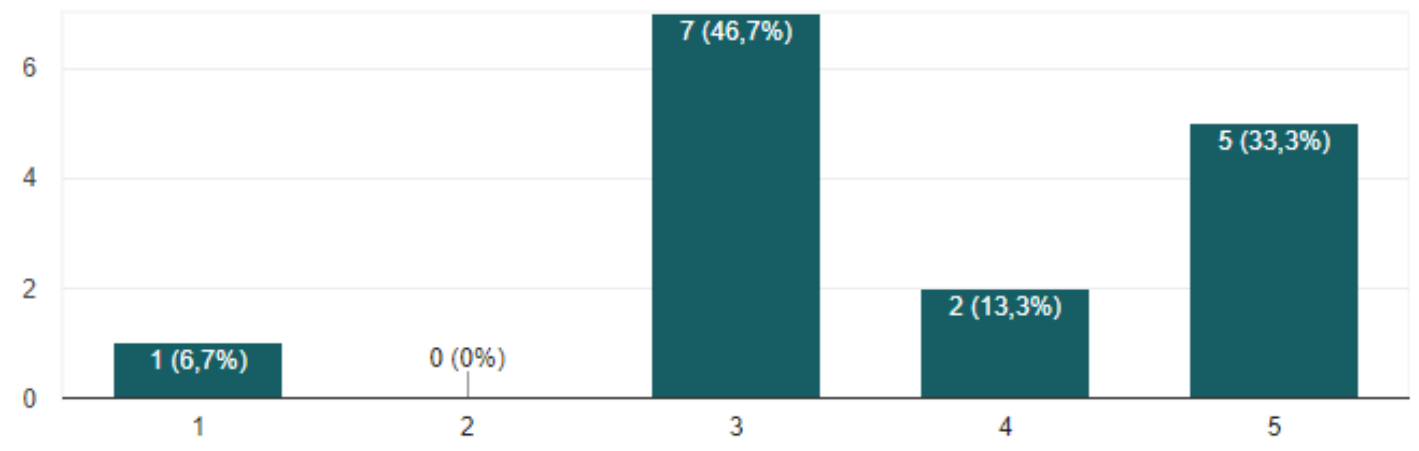

Figura 2 - Gráfico dos resultados obtidos com relação a entendimento de diálogos

O feedback em relação aos comandos do jogo apresentaram resultados satisfatórios, porém percebemos a necessidade de realizarmos algumas alterações para que o jogo fique ainda mais interativo. 


\section{Facilidade de entender os comandos}

15 respostas

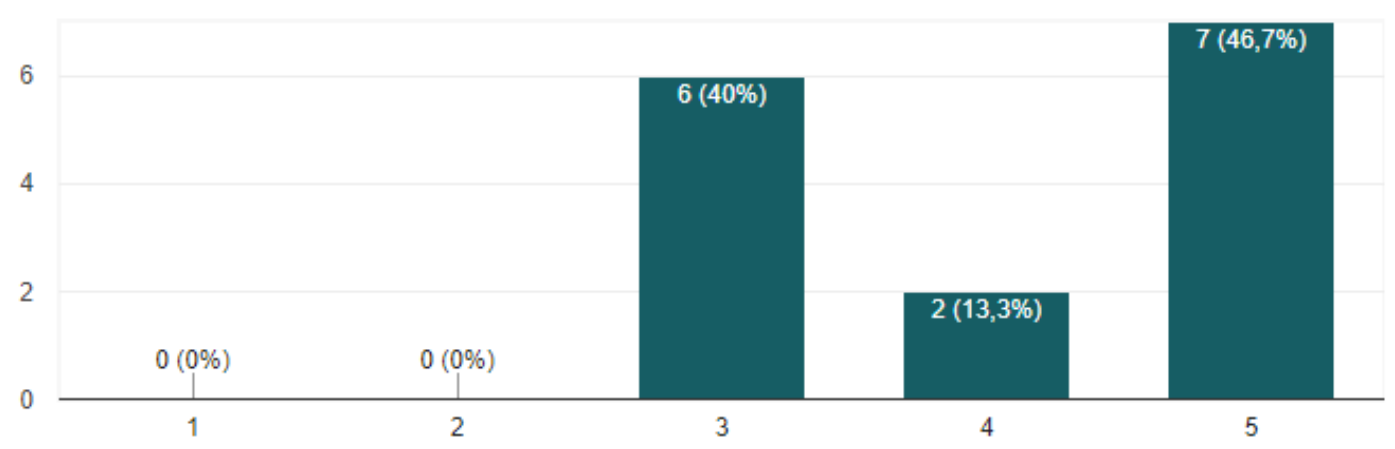

Figura 3 - Gráfico dos resultados obtidos com relação à compreensão dos comandos

Dentre os resultados obtidos destacamos que os alunos deficientes visuais interessaramse pelo jogo, de modo que os desafios lançados ao longo das partidas foram resolvidos com êxito. Além disso, avaliando os conhecimentos conceituais de português e matemática, os docentes do CAEDV consideraram que foram adequados à idade dos seus alunos. Houve também interação entre os alunos para a resolução dos desafios uma vez que havia variações de níveis entre eles. E o componente interdisciplinar possibilitou integração de outros conhecimentos para a resolução dos problemas que superaram a dicotomia disciplinar muitas vezes presente na sala de aula. Assim, constatamos que o Audio Game pode tornar a aprendizagem mais significativa, integrando o componente afetivo do jogo aos conceitos que são aprendidos em sala de aula. Possibilitando também às crianças e jovens com deficiência visual uma melhor integração com o mundo dos games e do RPG, tornando-os uma importante ferramenta para o ensino e a aprendizagem.

Ainda sobre os resultados, testamos o jogo com pessoas de diferentes idades, e também sem algum tipo de deficiência visual. Tivemos uma boa resposta sobre a facilidade de compreensão dos comandos, com cerca de $46 \%$ dos usuários avaliando o jogo com nota máxima neste quesito. Quanto à velocidade de narração da história, os usuários cegos relataram certa dificuldade em acompanhar. já os usuários videntes não relataram problemas quanto a isso. Esta dificuldade está sendo resolvida com as atualizações que estão sendo feitas no jogo. Além disso, os jogadores também se interessaram pela história do jogo, avaliando-a como interativa por conta de seu sistema de batalhas.

Em geral, os resultados foram bons, e as críticas foram construtivas. Devemos alterar, principalmente, a velocidade do som, colocando várias opções de velocidade. Vamos melhorar também o sistema de luta, para tornar o jogo ainda mais interativo e dinâmico.

\section{Considerações finais e Trabalhos futuros}

Este trabalho apresenta uma visão geral sobre a importância dos jogos no Ensino Fundamental, bem como sobre a inclusão das crianças deficientes visuais, através da utilização 
de jogos digitais no ensino. Os conceitos apresentados, em conjunto com dados levantados durante o processo de pesquisa, apontam a necessidade do desenvolvimento de jogos educativos para crianças e adolescentes deficientes visuais como metodologia de apoio ao ensino convencional, principalmente utilizando a linguagem portuguesa e matemática. Em trabalhos futuros, com a finalização do desenvolvimento deste Audio Game, objetiva--se apresentar o jogo a diversos Centros de Atendimento Especializado para Deficientes Visuais do Oeste do Paraná, visando mensurar quantitativa e qualitativamente sua eficácia tanto do ponto de vista dos alunos quanto de seus professores. Posteriormente, o jogo será disponibilizado em plataforma livre para a comunidade em geral através de website específico do projeto.

\section{Referências}

Barboza, A. F.; Martins, R. O.; Santos, H. R. M. (2013) “Uma Experiência no Ensino de

Informática para Deficientes Visuais no Município de Garanhuns/ -PE”, in: II Congresso Brasileiro de Informática na Educação (CBIE 2013), Campinas/SP, pg. 389 - -398, 2013.

Brasil. (1996) "Lei no 9.394, de 20 de dezembro de 1996. Lei de Diretrizes e Bases da

Educação Nacional”. Site do Ministério da Educação (MEC) do Governo Federal Brasileiro, http://portal.mec.gov.br/arquivos/pdf/ldb.pdf

Correa, A. G. D.; Oliveira P. A.; Biase, L. C. C.; Damon. D. L.; Lopes R. D. (2015)

"Sistema de Avaliação Didática Acessível Portátil para Pessoas com Deficiência Visual: estudo de caso com a plataforma Android" In: Artigo do Anais do XXVI Simpósio Brasileiro de Informática na Educação (SBIE 2015).

Hsiao, Hui-Chun. (2007) “A Brief Review of Digital Games and Learning”. The First IEEE International Workshop on Digital Game and Intelligent Toy Enhanced Learning. Los Alamitos, CA, p. 124 - -129, 2007.

Japiassu, H. (1976) “Interdisciplinaridade e Patologia do Saber”. Rio de Janeiro:Imago, 1976.

Lévy, P.; Medina, M. (2007) "Cibercultura: informe al Consejo de Europa”. Ciencia, Tecnología Y Sociedad, 16, 230. Bogotá, 2007.

Mariano, M. R. (2010) Desenvolvimento e avaliação de jogo educativo para cegos: acesso à informação sobre uso de drogas psicoativas (Dissertação). Universidade Federal do Ceará: Fortaleza.

Salton B. P.; Maia, N.; Rosito, M. C. (2011) "Inclusão Social e Digital de Alunos com Deficiência Visual: um Estudo Comparativo entre Leitores de Tela" In: Anais XXII SBIE - XVII WIE.

Siqueira, H. M.; Martini, L. C. (2010) "MATVOX - Um aplicativo para deficientes visuais que proporciona a implementação de algoritmos e cálculos matemáticos em um editor de texto”. Simpósio Brasileiro de Informática na Educação (SBIE) 2010, João Pessoa. 
VI Congresso Brasileiro de Informática na Educação (CBIE 2017)

Anais do XXVIII Simpósio Brasileiro de Informática na Educação (SBIE 2017)

Siqueira, M. Das G; S.; Aguillera, F. (2015) "Modelos e Diretrizes para uma Educação Inclusiva: Revisão de Literatura.” Revista Educação Especial, Santa Maria, p. 281 - 294.

Sens, A. L.; Pereira, A. T. C. (2015) Reflexões sobre o design de jogos digitais acessíveis: casos papa sangre e blindside. In: $7^{\circ}$ congresso nacional de ambientes hipermídia para aprendizagem. São Luiz, Maranhão.

Tajra, S. F. (2002) "Informática na educação: novas ferramentas pedagógicas para o professor na atualidade”. $4^{\mathrm{a}}$ edição, São Paulo: Érica.

Tripp, David. (2005) "Pesquisa--ação: uma introdução metodológica”. In: Educação e Pesquisa, São Paulo, v. 31, n. 3, p. 443-466, set./dez.

Veen, W.; Vrakking, B. (2009) "Homo Zappiens: educando na era digital”. Porto Alegre.

Yuan, B.; Folmer, E.; Harrys Jr., F. C. (2011) “Game accessibility: a survey”, in: Journal of Universal Access in the Information Society, vol. 10, ed. 1, pg. 81-100. 